\title{
Identidade, subjetividade e alteridade nas relações entre universos global/local e letramentos dominantes/vernaculares
}

\author{
Mary Elizabeth Cerutti-Rizzatti* \\ Kamila Caetano Almeida*
}

\begin{abstract}
Resumo
Este artigo veicula uma proposição teórica que tem como tema 'letramento e identidade', focalizando a constituição da subjetividade no encontro com a alteridade, assim como focalizando relações entre 'universo global' e 'universo local' no que tange aos usos da escrita e relações entre esses universos e os letramentos 'dominantes' e 'vernaculares'. Propõem-se ressignificações na compreensão das interfaces entre esses conceitos, fazendo-o em uma articulação entre a antropologia da linguagem no que respeita aos estudos do letramento, a filosofia da linguagem no âmbito do ideário bakhtiniano e a psicologia da linguagem no que concerne ao pensamento vygotskiano. Advoga-se em favor de uma compreensão dialógica entre as dimensões 'global' e 'local' da escrita, em relações com a ontogênese e a sociogênese, e se discutem implicações dessa proposição teórica no potencial interpretativo que traz consigo para estudos no campo da Linguística Aplicada.

Palavras-chave: Identidade. Subjetividade e alteridade. Universos global e local. Letramentos dominantes e vernaculares.
\end{abstract}

\section{Introdução}

Neste artigo, materializamos nossa vontade de discutir identidade na interface entre os estudos do letramento, o dialogismo bakhtiniano e o ideário vygotskiano. Essa proposição deriva de uma busca que vimos empreendendo em nosso grupo

*Professora do Programa de Pós-graduação em Linguística da Universidade Federal de Santa Catarina. 
de estudos ${ }^{1}$ de conceber a língua à luz da filosofia da linguagem bakhtiniana, da antropologia da linguagem, no que respeita aos usos sociais da escrita, e da psicologia da linguagem vygotskiana (CERUTTI-RIZZATTI; MOSSMANN; IRIGOITE, 2013). Nesse movimento, temos compreendido, a partir de Street (1984), de Kleiman (1995), de Barton (1994), de Hamilton, Barton e Ivanič (2000), entre outras abordagens afins, que os usos da escrita se dão necessariamente em contextos social, cultural e historicamente situados, o que implica uma concepção de sujeito corpóreo historicizado, que se constitui na relação com o outro, compreensão que nos remete a conceitos como intercorporeidade e encontro, propostos por Ponzio (2010) na perspectiva bakhtiniana e às relações entre sociogênese e microgênese sob o olhar de Vygotsky (1997).

Assim, enquanto os estudos do letramento nos são caros pela ótica sob a qual tomam os usos da escrita, em proposições que necessariamente nos levam ao exercício da compreensão acerca da forma com que diferentes grupos culturais lidam com essa modalidade da língua, entendemos necessário, nesse mesmo exercício de compreensão, lidar também com uma perspectiva mais efetivamente vinculada à discussão das implicações das relações intersubjetivas que têm lugar nesses mesmos grupos em se tratando do encontro entre o eu e o outro nas interações mediadas pela escrita, discussão que nos coloca em convergência com o ideário bakhtiniano.

Em nossa compreensão, é nesses encontros que se dá a constituição da subjetividade, o que implica discutir identidade necessariamente na correlação com a 'alteridade' e, em se tratando dos usos da escrita, fazê-lo, ainda, na tensão entre aqueles usos conhecidos e familiares da escrita e usos outros, desafiadores porque não pertinentes ao cotidiano de um grupo cultural específico e dos encontros que têm lugar nele; eis, aqui, a demanda por uma reflexão acerca dos universos global e local(is) e, por implicação, uma reflexão acerca dos letramentos vernaculares e dominantes.

Assim, este artigo propõe-se a discutir identidade no encontro com a alteridade; nesse caso específico, um encontro mediado pela modalidade escrita da língua, um encontro, portanto, situado na sociedade, na cultura e na história e, sendo assim, em grupos culturais específicos, requerendo, pois, de um olhar que se queira

1 NELA - Núcleo de Estudos em Linguística Aplicada da Universidade Federal de Santa Catarina. 
academicamente analítico, sensibilidade aos usos da escrita que são característicos desses mesmos grupos, tanto quanto àqueles usos que lhe são exteriores, mas que tendem a tentar/forçar se impor, porque são legitimados como dominantes sob a égide da ampla historicização de vozes de que se constituem.

Para dar conta desse propósito, o artigo se divide em duas seções de conteúdo: na primeira delas, empreendemos uma discussão com foco na identidade, fazendo-o à luz da articulação teórica que mencionamos anteriormente; e na segunda seção, arvoramo-nos na tentativa de construção de novos caminhos para pensar os universos global e local(is) na relação com os letramentos dominantes e vernaculares. Nas considerações finais, registramos a fecundidade que entendemos haver, no esforço teórico levado a termo nas seções anteriores, para estudos no campo da Linguística Aplicada e, portanto, para estudos ocupados com problemas linguísticos socialmente relevantes, como quer Moita Lopes (2006), em se tratando do objeto de estudo consolidado no campo da LA.

\section{Constituição identitária: uma discussão sobre subjetividade no encontro com a alteridade}

Entendemos que ações de pesquisa ancoradas em um ideário histórico-cultural ${ }^{2}$ lidam com uma concepção de sujeito que se constitui na relação com o outro. Essa compreensão tem nos afastado de discussões de identidade com origem no indivíduo em si mesmo, afastamento que converge com Ponzio (2011, p. 267), o qual, à luz do ideário bakhtiniano, entende que a unicidade se constitui na relação com o outro, "a unicidade não subsiste fora da relação com a alteridade; é o outro que, na sua absoluta alteridade, chamando o eu à sua responsabilidade sem limites e sem justificativas, o produz único (PONZIO, 2011, p. 267)". "Trata-se, pois, da responsabilidade sem álibi", na qual cada um se encontra "na sua inalienável alteridade. Tal alteridade apresenta uma irredutível materialidade em relação à identidade, seja essa individual, como aquela de uma consciência ou de um eu, ou, ainda, coletiva, como aquela de uma comunidade (...) ou de um sistema cultural.” (PONZIO, 2011, p. 251) Segundo o

2 Para nós, estudos de base bakhtiniana na filosofia da linguagem; vygotskiana na psicologia da linguagem; freireana na pedagogia da linguagem, e com base nos estudos do letramento na antropologia da linguagem. 
autor, esse olhar evoca o deslocamento do centro da identidade à alteridade, remetendo à "revolução coperniciana" da crítica bakhtiniana da razão dialógica. E acrescenta: "Estamos diante do humanismo da alteridade, que considera que o fato primário da existência não é o ‘si mesmo' nem o 'para si', mas o ‘o outro'.” (PONZIO, 2011).

Assumindo, assim, a constituição do "eu" na relação com o "outro", entendemos não ser possível discutir identidade sob a perspectiva de um sujeito tomado em sua individualidade, em um necessariamente perene estado de instabilidade subjetiva em si mesma. Com isso, importa a ressalva, não advogamos em favor de nenhum tipo de estabilidade irredutível; tratamos, sim, de movências (GERALDI, 2010), mas de movências com ancoragens, concebendo âncoras como pontos temporários de fixidez, de uma fixidez flexível. (CERUTTIRIZZATTI; MOSSMANN; IRIGOITE, 2013). Entendemos que a metáfora da âncora converge com o zelo pela historicidade que necessariamente nos dá pontos de assossegamento, zonas temporárias de conforto; entendemos não ser possível negar essa estabilidade relativa quando assumimos a história e a cultura como lócus de compreensão teórica do homem, do mundo, da vida e, exatamente por isso, da linguagem, porque, em o fazendo, assumimos a relação "eu" e "outro" como gênese dessas movências.

Queremos, assim, ver as movências da subjetividade à luz da relação com a alteridade, uma relação marcada por essas mesmas movências, mas sempre situada no tempo e no espaço e, assim, nunca inteiramente fugaz, jamais gaseificada, não eternamente instável, porque inarredavelmente historicizada. E entendemos a história como o que o homem fez/faz entre o passado e o presente e entre o presente e o futuro, portanto como atividade humana consolidada na intercorporeidade que tem lugar no tempo e no/sobre o espaço. Eis, então, a mobilidade que nos agrada pensar: uma mobilidade gestada no encontro com o outro, sempre com raízes, caracterizando-se por prospecções que só se podem erigir sobre retrospectivas.

Assim, concebemos que uma discussão de identidade no imbricamento com os estudos do letramento requer de nós pensar que essa relação entre o "eu" e o "outro" se dá por meio da linguagem e, nesse caso específico, por meio da modalidade escrita da língua. Desse modo, no âmbito dos usos sociais da escrita, interessa- -nos entender como essa modalidade da língua medeia esse mesmo 
encontro do eu com o outro, no bojo do qual se dá a mútua constitutividade dos sujeitos. Sobre o 'encontro', escreve Ponzio (2010, p. 40, grifos do autor):

Não há primeira palavra de cada um e em seguida o encontro com a palavra outra à qual se dirige a da qual requer a escuta. Não há antes o eu e o outro, cada um com o que tem a dizer, e, em seguida, a relação entre eles. A relação não é entre eles, mas é justamente aquilo que cada um é no encontro da outra palavra com a palavra outra, e como não teria sido e não poderá ser fora daquele encontro.

O encontro seria, pois, em nosso entendimento, o lugar da constituição do sujeito e de sua configuração identitária e, para as finalidades deste artigo, interessa-nos compreender os encontros mediados pela modalidade escrita da língua: a outra palavra encontra-se com a palavra outra por meio da escrita e, em o fazendo, se reconhece na palavra outra, ou se distingue dela, ou comunga parcialmente com ela, ou se contrapõe frontalmente a ela, mas jamais a deixa sem algum tipo de resposta (VOLÓSHINOV, 2009); logo, jamais a deixa sem algum tipo de movência na própria subjetividade. Não saímos ilesos do encontro com a palavra outra, porque lidamos com a diferença não indiferente como quer Ponzio, já que a "alteridade apresenta uma irredutível materialidade em relação à identidade (PONZIO, 2010; 2011)" e focalizar o "outro" remete ao "problema da palavra, da palavra como voz reconhecida como demanda de escuta". (PONZIO, 2011, p. 251). E evocando aqui Bakhtin (2003) - uma remissão também feita por Ponzio (2007) -, importa mencionar que tudo o que é dito para a fala vale também, salvaguardadas as especificidades, para a escrita.

Esse encontro com a palavra outra por meio da escrita, situadamente no tempo, no espaço, na cultura e, portanto, na história, e a impossibilidade de sair dele sem movências em nossa constituição subjetiva nos remete a reflexões de Kramsch (1998) acerca de nossa condição de insiders ou outsiders nos diferentes entornos culturais. Ainda que a autora não empreenda essa discussão com o enfoque e as interfaces que propomos aqui, suas considerações sobre a importância do "outro" no reconhecimento do (não) pertencimento do "eu" a um lócus cultural específico parece-nos interessante na discussão que empreendemos. Segundo ela, a percepção do "eu" como insider em um determinado entorno cultural demanda 
o reconhecimento dessa mesma condição por parte dos "outros" ambientados/ legitimados nesse entorno; o mesmo valeria para a condição de outsider.

Entendemos, pois, que o compartilhamento identitário constrói-se na relação entre subjetividade e alteridade e, em se tratando dos usos sociais da escrita, entendemos que a natureza necessariamente situada desses usos na cultura, no espaço social e na história, demanda uma reflexão sobre esse mesmo pertencimento. Se tomarmos estudos de Ivanič (1998), de Lillis (2000) e de Zavala (2010) sobre experiências com a escrita na universidade, por exemplo, parecem-nos inequívocas essas mesmas relações: sentir-se parte da esfera acadêmica e ser reconhecido ou não como tal implica lidar diferentemente com os usos da escrita que têm lugar ali e seguramente repercutem na constituição subjetiva e na configuração identitária dos estudantes, reflexão da qual se ocupam essas autoras nessas obras e que nos parece passível de ser estendida para outras tantas esferas da atividade humana, tanto quanto para diferentes grupos sociais que se engendram no interior de cada qual dessas tantas esferas.

Desse modo, essa discussão entre configurar-se identitariamente como parte de um determinado lócus sociocultural e ser reconhecido ou não pelo "outro" como tal tem por base a relação entre subjetividade e alteridade. Para o recorte deste artigo, essa relação constitui-se em um encontro mediado pela escrita, o que nos remete a uma reflexão mais cuidada acerca do que entendemos serem os universos global e local e, por implicação, os letramentos dominantes e vernaculares, dos quais nos ocuparemos na próxima seção, tendo por base a compreensão de que não se trata de dicotomias, mas de lugares em dialogicidade e que serão discutidos na perspectiva de tal encontro historicizado entre o "eu" e o "outro", mediado pela escrita, encontro no qual se (re)configura a constituição identitária dos usuários da escrita.

\section{Estudos do letramento: os universos global e local e os letramentos 'dominantes' e 'vernaculares'}

A busca pela construção de novas inteligibilidades no que respeita aos universos global e local e sua relação com os letramentos dominantes e os 
letramentos vernaculares deriva de inquietações que têm nos ocupado a partir de Street (2003), o qual traz à tona tensões nas relações entre esses universos, deixando entrever a complexidade que entende existir nessas mesmas relações, tanto quanto a preocupação de que elas possam vir a ser tomadas na assepsia dessa mesma complexidade.

Essa é uma reflexão de que temos nos ocupado como grupo de estudos porque entendemos ser de substancial importância na compreensão de espaços socioculturais em que temos nos inserido em nossos processos de pesquisa, ${ }^{3} \mathrm{com}$ especial atenção àqueles de vulnerabilidade social. Nessas discussões, temos concebido que global não pode ser tomado como sinônimo de dominante, assim como local não pode ser tomado como sinônimo de vernacular, porque nos parece haver desdobramentos no interior dessas mesmas relações a demandar novas reflexões. Propomos, aqui, uma possível ótica para lidar com esses conceitos, na busca de novas interlocuções sobre tal temática na academia.

Nossa reflexão parte da compreensão de que, com base no ideário vygotskiano, no que respeita às reflexões sobre planos genéticos, poderíamos entender que a constituição do sujeito, no âmbito da microgênese, se dá nas relações interpsicológicas que têm lugar nas vivências culturais respectivas à sociogênese, mas há uma dimensão ontogenética e uma dimensão filogenética igualmente implicadas nesse processo de desenvolvimento sociocultural e psicológico (VYGOTSKY, 1997). Entendemos que, no âmbito da dimensão ontogenética, em que as especificidades culturais do(s) grupo(s) de inserção mais imediato(s) dos sujeitos não se visibilizam em suas particularidades, poderíamos compreender o que chamamos, aqui, de universo global: global porque respectivo a todos os seres humanos indistintamente.

Pensar assim implica conferir uma inespecificidade ao universo global, dado que quaisquer especificações necessariamente saem do âmbito da ontogênese para ter lugar no âmbito da sociogênese porque demandam intercoporeidade (PONZIO, 2011), e a intercorporeidade nunca é global porque é inarredavelmente situada no tempo e no espaço sociocultural, impondo-lhe, pois, escalas possíveis de globalidade, porque a corporeidade se move no tempo e no espaço sociocultural, mas só pode fazê-lo em

3 A exemplo de estudos como os de Euzébio (2011); Irigoite (2011); Pedralli (2011), desenvolvidos no âmbito do NELA/UFSC. 
frações nesses mesmos tempo e espaço; não há ubiquidade possível. Arriscamos mais: vincular global a ontogênese implica tratar de abstração, enquanto vincular local a sociogênese implica tratar de atração, no sentido que Gačev (2011) dá a essa relação: ABStract, do latim ab-stractus, "tirado de" versus ATtract, também do latim, "puxado em direção a". Uma reflexão dessa ordem, porém, poderia nos levar ao conceito de 'glocal' que tem surgido na literatura (ROBERTSON, 1992; KUMARAVADIVELU, 2006). Entendemos, no entanto, que não se trata de empreender uma simbiose entre os conceitos em renomeações tais quais, porque não os concebemos sob um olhar dicotômico; queremos entendê-los sob uma perspectiva dialógica, o que nos exime de renomeá--los. Voltaremos a essa perspectiva dialógica à frente.

Em se tratando dos usos da escrita, teríamos, nesse escopo global, aqueles usos necessariamente respectivos ao que entendemos ser uma vocação ontogenética do ser humano para compreender o mundo em sua constituição físico-biológica, tanto quanto para entender o homem em sua natureza corpóreo-psíquico-emocional, dentre outros desdobramentos congêneres, o que nos levaria ao campo das ciências em suas múltiplas configurações. Teríamos, também, usos da escrita respectivos a uma possível 'propensão ontogenética' humana para discutir a vida e o próprio ser humano nas relações consigo mesmo e com o mundo, o que nos levaria à filosofia em seus também vários desdobramentos. Haveria, ainda, escritos atinentes à característica humana de incidir sobre a realidade, à medida que a compreende mais efetivamente, $\mathrm{o}$ que nos remeteria às tecnologias de toda ordem, assim como, por outro lado, teríamos escritos relativos ao pendor humano para ressignificar o universo e o homem, o que nos levaria para as tantas formas de manifestações artísticas; e, enfim, mas longe de exaurir as possibilidades, teríamos escritos vinculados ao movimento humano para a transcendência, o que nos levaria para todas as formas de confissão religiosa ou manifestação da espiritualidade e afins.

Essa nossa assumidamente arriscada reflexão, que busca fôlego no plano ontogenético do desenvolvimento humano à luz do ideário vygotskiano, com os riscos que traz consigo, talvez possa contemplar o que vimos entendendo por universo global, ou seja, aquela dimensão abstrata, reverberada nos fazeres com a escrita, que historicamente ganhou espaços no mundo humano, quer para dar conta da vontade dos homens de saber mais sobre si mesmos e sobre o universo, quer para dar conta de sua vontade de transformar a si mesmos e ao universo. 
Quando, porém, tais fazeres com a escrita materializam tais propensões humanas, a abstração ontogenética do global se configura na atração sociogenética do local. Eis, então, o lócus em que os muitos encontros (PONZIO, 2010) com o outro têm lugar, processo a que se dispõem os homens por meio da palavra escrita e, fazendo-o por meio dela, não encontram apenas os homens de seu tempo histórico e de seu espaço imediato, mas projetam-se para outros tempos e para outros espaços, em encontros outros - sempre situados, na atração e nunca na abstração -, na medida em que essa sua vocação para incidir sobre o mundo lhes faculta ir mais além, movência da qual são prova - mais em uma metáfora do que em um exemplo - tanto a imprensa de Gutenberg como a nuvem do Google.

Assim, tais propensões humanas ganhariam materialidade, no universo local em usos da escrita vinculados tanto aos letramentos dominantes como aos letramentos vernaculares; ou seja, enquanto usos dominantes historicizariam as ciências, as artes, as religiões, a filosofia, etc. em representações carregadas de vozes apostas/ interpostas/sobrepostas, em vinculação com a ideologia oficial (BAKHTIN, 2011; VOLÓSHINOV, 2009) e em gêneros discursivos secundários (BAKHTIN, 2003a), haveria os usos vernaculares a lidar também com as ciências, as artes, a filosofia, a religiosidade em representações carregadas de vozes apenas locais, no âmbito da ideologia não oficial. Concebemos ambos os movimentos em dialogia, tal qual mostraremos à frente. Por ora, apenas buscamos a compreensão de que os usos da escrita do universo global quando se materializam no universo local não o fazem tão somente no plano dos letramentos dominantes, mas também dos vernaculares, se não por outras razões, pela inarredável variabilidade dos encontros entre os homens em seu lócus sociocultural e histórico, encontros mediados pela escrita.

Nessa busca por criar inteligibilidades para o que chamamos aqui de universo global em se tratando da escrita, recorremos, então, a Kalantzis e Cope (2000) e a seu conceito de horizontalização. Propomos uma interface entre esse conceito e a concepção de global (STREET, 2003), em uma compreensão de global como o que está horizontalizado - eis a metáfora da linha do horizonte -, sendo extensível, no âmbito filosófico das potencialidades, a todos os seres humanos indistintamente, porque a vocação humana para as ciências, a filosofia, as artes, a religiosidade e afins, vincular-se-ia à ontogênese, o que ligaria esses usos aos sujeitos em suas diferentes inserções socioculturais; logo, à abstração da efetiva intercorporeidade. 
Assim, temos concebido o universo global dos usos da escrita como imbricado à infinita extensão da horizontalidade da escrita no mundo humano - o lócus do que é potencial, insistimos, no sentido filosófico do termo -, a qual diz respeito a todos nós em razão de nossa filiação ontogenética, mas da qual alguns, na configuração de suas relações intersubjetivas/intercorpóreas, se aproximam mais efetivamente do que outros, em profundidade e/ou em extensão; ninguém, porém, pode dar conta de apreendê-la em sua totalidade, exatamente porque a horizontalidade é o território do que é potencial, é o plano da abstração ontogenética. Essa proposição metafórica nos faz compreender que tal universo global necessariamente se materializa, em múltiplas miríades, em cada universo local, porque damos conta, diferentemente, desses espectros na mencionada horizontalidade, e eles correspondem aos limites do que conseguimos vivenciar no âmbito de nossa condição corpórea, necessariamente situada no tempo, no espaço e na cultura de que somos parte, o nosso mundo de letramento, tal qual propõem Hamilton, Barton e Ivanič (1993) no reconhecimento da pluralidade desses "mundos".

Na sequência, tentamos representar em diagramas essa relação: teríamos uma linha de horizontalidade contínua dos usos da escrita - a vinculação à ontogênese humana -, constituída por e em relação dialógica com materializações localizadas desses usos, as quais, por sua vez, estariam igualmente em relações dialógicas entre si. A simetria das setas obedece a fins de representação figurativa, sem denegar sua necessária singularidade, o que nos levaria a setas de formatação distintas umas das outras, escolha da qual fugimos na busca de evitar representações que pudessem suscitar algum tipo de compreensão hierárquica, a exemplo de privilegiamento de tamanhos ou formas específicas. Fica o risco. Assim, no Diagrama 1, a seguir, a linha superior contínua corresponderia ao 'universo global' na vinculação com a ontogênese; já as setas de múltiplas pontas, em linha contígua, ligadas à linha superior, corresponderiam aos "universos locais" - agora já assumidamente plurais -, vinculados à sociogênese.

Eis o diagrama: 
Linha contínua da horizontalidade - usos da escrita imbricados à ontogênese humana

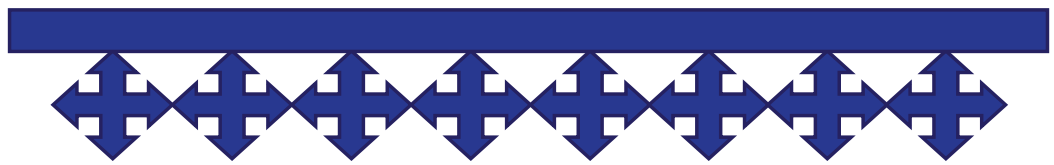

Materializações contíguas da horizontalidade em contextos socioculturais distintos

Diagrama 1 - Relações entre universos global e local

Fonte: proposição das autoras.

Nessa representação do Diagrama 1, o imbricamento entre todos os componentes parece-nos de fundamental importância porque, nessa articulação figurativa, tentamos materializar o dialogismo que entendemos haver nas movências que esses elos trazem consigo, tomados necessariamente como em mútua incidência uns sobre os outros. Importa ressaltar, ainda, que, na base das setas de múltiplas pontas, não há outra linha - uma possível linha paralela à superior, fechando o diagrama na horizontalidade. Trata-se de uma abertura propositada, que contempla as especificidades do que é essencialmente vernacular, atinente à mais absoluta singularidade de cada uma dessas setas, como mostraremos no Diagrama 4, à frente. Eis 'pontos de fuga', o singular, o exótico, o pitoresco e, enfim, o que provoca estranhamento porque não é reconhecível na horizontalidade das circunvizinhanças e não significa de fato a elas, e que, exatamente por isso, é tanto objeto de interesse antropológico - e, no nosso caso, linguístico - quanto objeto de preconceito e de exclusão. É diferente, é “outro", demanda escuta (PONZIO, 2010) mais atenta, porque é necessariamente tão humano quanto os demais usos.

Conceber essas relações tal qual propomos no Diagrama 1 permite-nos fugir de lidar com elas em um movimento entre margens e centro, porque um movimento de natureza esférica implica a existência de um componente central em relação ao qual o restante será necessariamente marginal. Kalantzis e Cope (2000) advertem para o risco de, em percepções tais, assumirmos uma falsa tolerância às margens, na efetiva intenção de impormos as representações centrais, o que os autores chamam de multiculturalismo. Mesmo que se advogue em favor de denegar às margens 
condição de marginalidade, essa condição lhes é inerente em representações como a que segue no Diagrama 2.

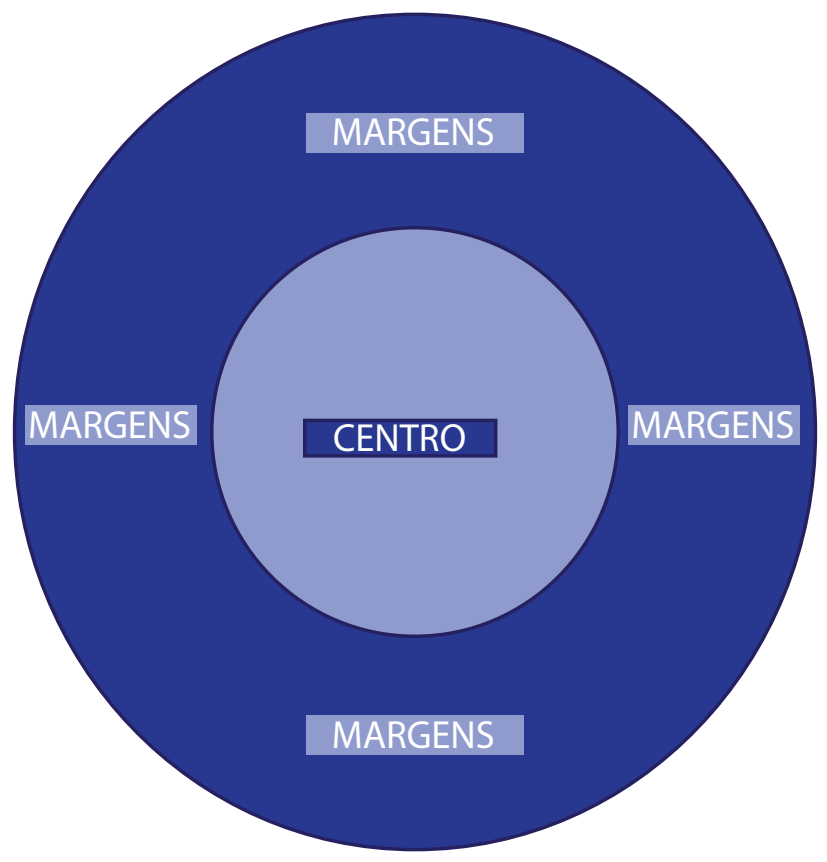

Diagrama 3 - Os "letramentos dominantes" constituindo-se na horizontalidade dos "universos locais"

Fonte: Proposição das autoras.

Entendemos que conceber as relações entre global e local, dominante e vernacular sob perspectivas como essa representada no Diagrama 2 faculta aposições de abstrações globais em detrimento de atrações locais, tanto quanto aposições do que é dominante ao custo do silenciamento do que é vernacular, pois implica uma centralidade em relação à qual há uma marginalidade. Na verdade, quer nos parecer que essa é a lógica da sociedade neoliberal contemporânea, na qual as relações de dominância se aplicam a questões culturais de toda ordem, do que não fogem os usos da escrita. Kalantzis e Cope (2000) entendem que historicamente esse movimento entre o que é legitimado e o que não é legitimado tem sido de flagrante exclusão das margens, ou de exigência de acomodação das 
margens em relação ao centro, ou, ainda, de falso reconhecimento da legitimidade das margens desde que se movam na convergência com o centro. A proposição de horizontalização dos autores, em nosso entendimento, abre uma nova possibilidade de lidar com essas representações, porque não fecha em círculo, concebendo a relação em uma linha de infinitudes, apostas lado a lado em relação. Diagramamos, assim, em um ensaio interpretativo, nossa compreensão da metáfora dos autores.

Assim, entendemos que metaforizar essa discussão dos usos da escrita com a figura da horizontalização nos permite fugir dessa dicotomia 'centro versus margens', favorecendo uma compreensão mais efetivamente comprometida com a condição situada desses mesmos usos (HAMILTON; BARTON; IVANIČ, 2000) e, portanto, com a impossibilidade de hierarquizá-los em níveis (BARTON, 1994), assumindo a diversidade de que trata Street (1984) em atenção à lógica segundo a qual cada grupo cultural usa a escrita a seu modo, em uma relação dialética entre global e local(is), o que entendemos possível compreender como a relação entre a ontogênese e a sociogênese, à luz do ideário vygotskiano.

Assim, tendo presente a representação materializada no Diagrama 1, concebemos os usos da escrita situados em cada grupo cultural (HAMILTON; BARTON; IVANIČ, 2000) - cada qual das setas de múltiplas pontas -, construídos no movimento sociogenético (VYGOTSKY, 1997). Esse olhar, porém, requer de nós a aposição de uma lente mais acurada no âmbito desses próprios grupos culturais, ou seja, no espectro de cada qual dessas materializações em cada um dos universos locais - cada qual das setas de múltiplas pontas no Diagrama 1. Ali, em nossa percepção, instauram-se as tensões entre os usos da escrita, porque ali estão os sujeitos em intercorporeidade (PONZIO, 2010a); ali se materializa a cadeia discursiva, com a carga ideológica que lhe é peculiar (VOLÓSHINOV, 2009).

Nessas materializações dos usos da escrita nos universos locais, nos encontros (PONZIO, 2010) entre os sujeitos em seus mundos de letramento (HAMILTON; BARTON; IVANIČ, 1993), emergem usos aos quais se confere condição de dominantes em contraposição a usos aos quais se confere condição de vernaculares. A que se deveria cada qual dessas condições? Entendemos que essa discussão nos remete à historicização das vozes em cada um desses usos, tanto quanto a reflexões sobre as relações entre ideologia oficial e ideologia não oficial (BAKHTIN, 2011; VOLÓSHINOV, 2009). Na perspectiva do Círculo de 
Bakhtin, os sistemas ideológicos estáveis, derivados da ideologia formalizada ou oficial, gestam-se a partir dos sistemas instáveis, imbricados com as ideologias do cotidiano. Tais sistemas ideológicos estáveis, que remetem às ciências, às artes, ao direito entre outros campos da atividade humana, "cresceram e se cristalizaram a partir do elemento ideológico instável, que através das ondas vastas do discurso interior e exterior banham cada ato nosso e cada recepção nossa." (BAKHTIN, 2011, p. 88). Entendemos essas "ondas vastas de discurso interior e exterior" como o conjunto de vozes historicizado que se apõe a determinados usos da língua - para nosso foco, da escrita -, historicizando tais usos em um espectro mais efetivamente amplo da convivência humana.

Retomando nossas proposições do Diagrama 1, tais usos dominantes - embora sempre locais, porque materializados no encontro corpóreo entre os sujeitos, encontro no qual essa aposição de vozes se historiciza - corresponderiam ao imbricamento horizontal entre as setas, àqueles usos que perpassam as setas entre si, ganhando uma amplitude maior na horizontalidade da linha e incidindo mais efetivamente sobre a configuração sempre móvel dessa mesma linha. Tentemos ser mais explícitas, representando no Diagrama 3, a seguir, esse olhar, com enfoque no imbricamento horizontal entre as setas, tomadas sob uma lente mais próxima.

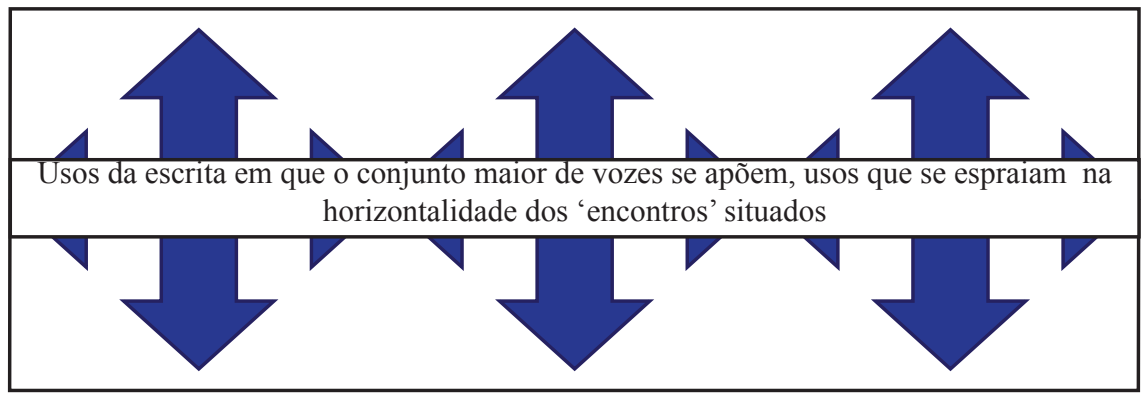

Diagrama 4 - Os letramentos vernaculares constituindo-se na verticalidade dos universos locais

Fonte: Proposição das autoras.

Ainda sob essa lógica e, agora, trazendo a lente para o interior de cada grupo cultural, os domínios de que trata Barton (1994), encontraríamos ali os letramentos vernaculares, concebendo-os como aqueles usos da escrita mais 
efetivamente relacionados ao cotidiano desses mesmos grupos, o que nos levaria novamente ao Círculo de Bakhtin e à ideologia do cotidiano, que, segundo Miotello, é aquela que "brota e é constituída nos encontros casuais e fortuitos, no lugar do nascedouro dos sistemas de referência, na proximidade social com as condições de produção e reprodução da vida."(MIOTELLO, 2007, p. 169). Assim, os "letramentos vernaculares" estariam ligados ao cotidiano desses grupos específicos e à historicidade que se gesta ali, sem maior imbricamento, no plano da horizontalidade, conforme Diagrama 3, com os usos da escrita que têm lugar nos grupos circunvizinhos, mas evidentemente, ainda em dialogia com eles. Para dar conta disso, arrisquemos, então, uma última representação:

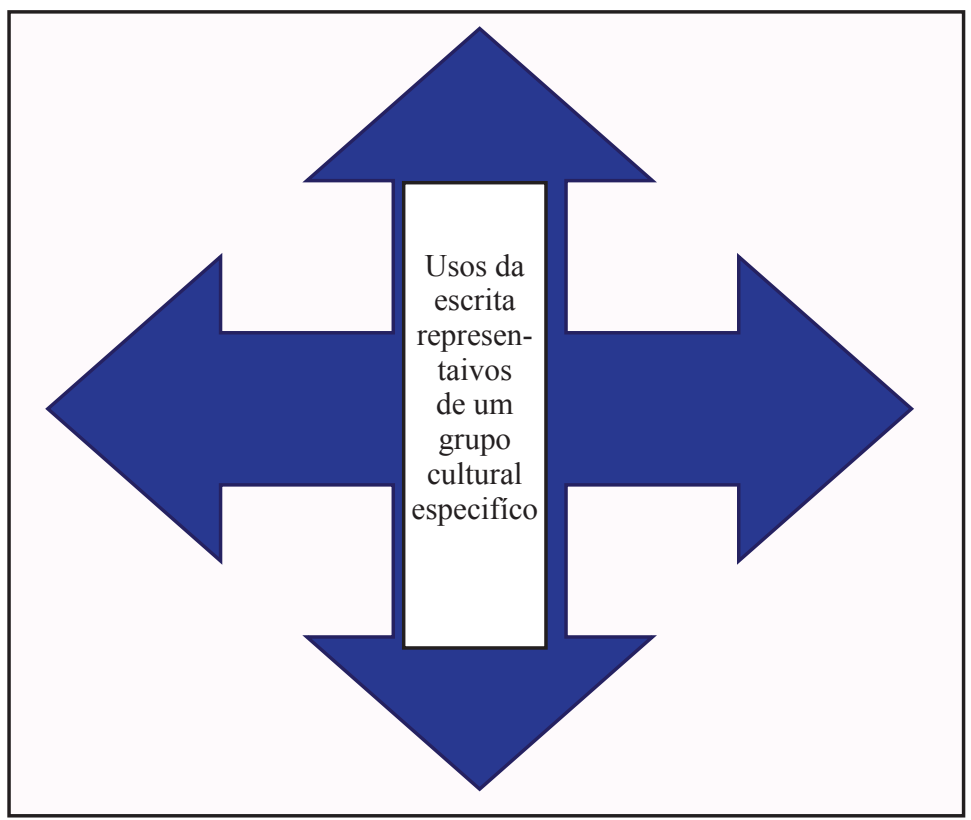

Assim, nos Diagramas 1, 3 e 4, representamos nossa proposição para a compreensão das relações entre o universo global e, agora no plural, os universos locais e, por implicação, entre os letramentos dominantes e os letramentos vernaculares. Na síntese a que se propõe este fecho de seção, vale registrar que o global demandaria um olhar para a ontogênese, enquanto que o(s) local(is) demandaria(m) um olhar para a sociogênese. Quanto ao global, vincular-se-ia à abstração, enquanto o(s) local(is)'vincular-se-ia(m) à atração (GAČEV, 2011). O global, então, quando materializado, necessariamente se 
converte no(s) local(is), fazendo-o quer sob forma de letramentos dominantes, quer sob forma de letramentos vernaculares.

Assim, as relações entre usos dominantes e usos vernaculares teriam de ser estudadas necessariamente no(s) âmbito(s) local(is), lócus onde se dá a materialização do universo global, porque, reiteramos, quando os usos globais se concretizam, só podem fazê-lo no plano situado. Essa materialização, por sua vez, lida com a tensão entre os usos dominantes e aqueles vernaculares. Os dominantes corresponderiam àqueles usos da escrita em que se apõem muitas vozes em historicização e que, nessa condição, transcendem os limites de cada grupo cultural, espraiando-se entre dimensões sociogenéticas distintas e imbricando-se em outras e outras vozes, o que nos levaria ao conceito de ideologia oficial do Círculo de Bakhtin (BAKHTIN, 2011; VOLÓSHINOV, 2009). Já os letramentos vernaculares corresponderiam a usos da escrita cuja historicização de vozes tende a se erigir mais efetivamente no plano de cada grupo cultural específico, verticalizando-se nele, mesmo que nunca insularmente, porque os universos locais estão imbricados em dialogia em sua gênese, e o estão exatamente pelo compartilhamento ontogenético que necessariamente os caracteriza e que, a seu turno, se deixa ver na linha da horizontalidade global. Tais verticalizações arvorar-se-iam idiossincrasias, o que a ponta em aberto em cada uma das setas deixa entrever.

\section{Considerações finais: fecundidade desta discussão no âmbito da Linguística Aplicada}

A concepção de constituição da subjetividade na relação com a alteridade de que nos ocupamos na primeira seção deste artigo e que nos impele a pensar identidade nas movências do encontro entre o "eu" e o "outro" (PONZIO, 2010; GERALDI, 2010) -, tanto quanto a proposição de uma discussão sobre relações entre universo global, universos locais e letramentos dominantes e letramentos vernaculares, vem se gestando com esses contornos em nosso grupo de estudos movida pela vontade de entender melhor o que acontece com a escrita em entornos de vulnerabilidade social. 
Vários dentre nossos estudos (IRIGOITE, 2011; EUZÉBIO, 2011; GOULART, 2012; CHRAIM, 2012; PIRES, 2013) têm sinalizado para dificuldades que temos, como estudiosos da língua materna, em compreender por que razão determinados entornos socioculturais parecem herméticos ao aprendizado de usos dominantes da escrita da forma não raro polêmica como tais usos vêm sendo ensinados (ÉRNICA; BATISTA, 2011). Em um olhar paulatinamente mais atento, temos compreendido que muitos desses usos não significam efetivamente para os sujeitos com que temos lidado porque não têm lugar nos encontros que eles estabelecem com os seus, no âmbito dos grupos culturais nos quais são de fato insiders (KRAMSCH, 1998). Por outro lado, quando lhes é demandado transitar - porque não se trata de inserção de fato - por outros espaços nos quais os usos dominantes têm lugar (a exemplo da escola, da universidade, da esfera jurídica, da esfera religiosa e afins), parecem exercitar um esforço de distinção, mantendo-se na condição de outsiders e, não raro, aparentemente se recusando a ensaiar um movimento de inserção mínima pelo compartilhamento dos usos que são caros nesses espaços.

Resultados de pesquisa dessa ordem nos têm feito compreender que se identificar com determinados usos da escrita tidos como representativos dos letramentos dominantes - a exemplo de romances consagrados na literatura universal, ensaios científicos veiculados em artefatos (HAMILTON, 2000) legitimados por instituições de prestígio sociocultural e representações congêneres - implica transcender a condição de 'mover-se' nas esferas da atividade humana em que esses usos têm lugar, para assumir a condição de 'inserir-se de fato' nessas mesmas esferas. Dizendo de outro modo e à luz de Kramsch (1998), implica reconhecer-se como insider nessas esferas e ser reconhecido pelo(s) outro(s) como tal. Ivanič (1998), Lillis (2000) e Zavala (2010) parecem mostrar isso muito bem em relação à universidade.

Trata-se, pois, de um processo de constituição da subjetividade na alteridade, tanto quanto se trata de um processo de horizontalização de representações de mundo, de modo a sair de uma possível insularidade no universo de um grupo cultural específico - uma única dentre as setas - e transcender os domínios vernaculares da escrita para efetivamente inserir-se em um espectro maior da linha do horizonte - outras dentre as setas de múltiplas pontas em contiguidade no Diagrama 1-, estabelecendo, assim, relações intersubjetivas - e, por implicação, intercorpóreas - em outras "setas" para além da sua. 
Esse parece ser o desafio dos processos de escolarização em língua materna no que respeita à escrita: educar para essa horizontalidade, atitude que requer compreender manifestações vernaculares, tanto quanto conferir sentido às proposições de manifestações dominantes, não no sufocamento do que é vernacular, tal qual pode se dar em ações de centro e margem como representamos no Diagrama 2, mas em ações que facultem ao sujeito o ir e vir entre o que é efetivamente representativo de sua inserção cultural e o que lhe é externo, mas está em dialogia potencial com o que lhe é familiar. Para que um processo dessa ordem se dê, parece-nos não haver outro caminho senão a experimentação, a vivência, o encontro com o "outro" por meio da escrita, com o "outro" que não é tão próximo, porque transcende o vernacular. Para isso, importa que o encontro signifique, e ele só pode significar quando o encontro (PONZIO, 2010) de fato implicar a vivência da palavramundo (FREIRE, 2006), porque é na vivência facultada pelo encontro com o "outro" que nos constituímos como sujeito, provocando movências em nossa (re)configuração identitária.

\title{
Identity, subjectivity and otherness in the relationships between global/local universes and dominant/vernacular literacies
}

\begin{abstract}
This article conveys a theoretical proposition whose theme is 'literacy and identity', focusing on the constitution of subjectivity in the encounter with otherness, as well as focusing on relationships between 'global universe' and 'local universe' in terms of the uses of writing and relationships between these universes and 'dominant' and 'vernacular' literacies. Resignifications in understanding the interfaces between these concepts are proposed, making it in a relationship between the anthropology of language with regard to studies of literacy, the philosophy of language in the scope of Bakhtin's thinking and the psychology of language in relation to Vygotskyan's thinking. There have been advocates in favor of a dialogical understanding between 'global' and 'local' dimensions of writing, in relations with the ontogenesis and sociogenesis, and also implications of this theoretical proposition in the interpretative potential which it has for studies in the field of Applied Linguistics are discussed.
\end{abstract}

Keywords: Identity. Subjectivity and otherness. Global and local universes. Dominant and vernacular literacies. 


\title{
Identité, subjectivité et altérité dans les rapports entre les univers mondial/local et les littéracies dominantes/vernaculaires
}

\begin{abstract}
Résumé
Cet article fait une proposition théorique ayant pour sujet "la littéracie et l'identité" tout en mettant en relief la constitution de la subjectivité dans sa rencontre avec l'altérité, aussi bien que les rapports entre "univers global" et "univers local" en ce qui concerne les usages de l'écriture et les rapports entre ces univers et les littéracies "dominantes" et "vernaculaires". On y propose des re-significations dans la compréhension des interfaces entre ces concepts dans une articulation entre l'antropologie du langage, en ce qui concerne les études de la littéracie, la philosophie du langage dans le contexte de l'abordage bakhtinien et la psychologie du langage en ce qui concerne la pensée vygotskienne. On y défend une compréhension dialogique entre les dimensions "globale" et "locale de l'écriture, en rapport avec l'ontogenèse et la sociogenèse. On y discute également les implications de cette proposition théorique dans le potentiel interprétatif qu'elle apporte pour les études dans le domaine de la Linguistique Appliquée.
\end{abstract}

Mots-clés : Identité. Subjetivité et altérité. Univers global et univers local. Littéracies dominantes et vernaculaires.

\section{Referências}

BAKHTIN, Mikhail. Estética da criação verbal. Tradução de Paulo Bezerra. 4. ed. São Paulo: Martins Fontes, 2003. Original publicado em 1979.

BAKHTIN, Mikhail. Os gêneros do discurso. In: BAKHTIN, Mikhail. Estética da criação verbal. Tradução de Paulo Bezerra. 4. ed. São Paulo: Martins Fontes, 2003a. p. 261-306. Original publicado em 1952/53.

BAKHTIN, Mikhail. O freudismo: um esboço crítico. São Paulo: Perspectiva, 2011. Original publicado em 1927.

BARTON, David. Literacy: an introduction to the ecology of written language. Cambridge/USA: Blackwell, 1994. 
CERUTTI-RIZZATTI, Mary Elizabeth; MOSSMANN, Suziane da Silva; IRIGOITE, Josa Coelho da Silva. Estudos em cultura escrita e escolarização: uma proposição de simpósio entre ideários teóricos de base histórico-cultural na busca de caminhos metodológicos para pesquisas em Linguística Aplicada. Fórum Linguístico, v. 10, n. 5, 2013.

CHRAIM, Amanda Machado. Relações implicacionais entre desenvolvimento da consciência fonológica e instrução alfabética na educação de adultos inseridos em entornos sociais grafocêntricos. Dissertação (Mestrado em Linguística). Programa de Pós-Graduação em Linguística. Universidade Federal de Santa Catarina. Florianópolis, 2012.

ÉRNICA, Maurício; BATISTA, Antônio Augusto Gomes. Educação em territórios de alta vulnerabilidade social na metrópole: um caso na periferia de São Paulo. In: Informe de pesquisa, n. 3. São Paulo: Cenpec, 2011.

EUZÉBIO, Michelle Donizeth. Um estudo sobre práticas e eventos de letramento em uma comunidade escolar em Florianópolis/SC. Dissertação (Mestrado em Linguística). Programa de Pós-Graduação em Linguística. Universidade Federal de Santa Catarina, Florianópolis, 2011.

FREIRE, Paulo. A importância do ato de ler-Em três artigos que se completam. 47. ed. São Paulo: Cortez, 2006. Original publicado em 1985.

GAČEV, Georgij D. Ritratti di culture. Perugia: Guerra Edizione, 2011.

GERALDI, João Wanderley. A aula como acontecimento. São Paulo: Pedro e João Editores, 2010.

GOULART, Anderson Jair. Letramento familiar: práticas e eventos de leitura em segmento genealógico familiar com progenitores analfabetos. Dissertação (Mestrado em Linguística). Programa de Pós-Graduação em Linguística. Universidade Federal de Santa Catarina, Florianópolis, 2012.

HAMILTON, Mary. Expanding the new literacy studies: using photographs to explore literacy as social practice. In: BARTON, David; HAMILTON, Mary; IVANIČ, Roz (Org.). Situated literacies. London: Routledge, 2000.

IRIGOITE, Josa Coelho. Vivências escolares em aulas de Português que não acontecem: a (não) formação do aluno leitor e produtor de textos-enunciado. Dissertação (Mestrado em Linguística). Programa de Pós-Graduação em Linguística. Universidade Federal de Santa Catarina, Florianópolis, 2011. 
IVANIČ, Roz. Writing and identity: the discoursal construction of identity in academic writing. Amsterdam: John Benjamins, 1998.

KALANTZIS, Mary; COPE, Bill. Multiliteracies. London and NY: Routledge, 2000.

KLEIMAN, Angela Bustos. Modelos de letramento e as práticas de alfabetização na escola. In: KLEIMAN, Angela Bustos (Org.). Os significados do letramento: uma nova perspectiva sobre a prática da escrita. Campinas, SP: Mercado de Letras, 2001. p. 15-64. Original publicado em 1995.

KRAMSCH, Claire. Language and culture. NY: Oxford University Press, 1998.

KUMARAVADIVELU, B. A linguística aplicada na era da globalização. In: MOITA LOPES, Luiz Paulo da. Por uma linguística aplicada indisciplinar. São Paulo: Parábola Editorial, 2006.

LILLIS, Theresa M. Student writing: Access, Regulation, Desire. Londres: Routledge, 2001.

MIOTELLO, Valdemir. Ideologia. In: BRAIT, Beth (Org.). Bakhtin: conceitos-chave. 4. ed. São Paulo: Contexto, 2007. p. 167-176.

MOITA LOPES, Luiz Paulo da. Linguística Aplicada e vida contemporânea: problematização dos construtos que têm orientado a pesquisa. In: MOITA LOPES, Luiz Paulo da (Org.). Por uma linguística aplicada indisiciplinar. São Paulo: Parábola Editorial, 2006.

PEDRALLI, Rosângela. Usos sociais da escrita empreendidos por adultos alfabetizandos em programa educacional institucionalizado: dimensões extraescolar e escolar. 2011. 295 p. Dissertação (Mestrado em Linguística). Programa de Pós-Graduação em Linguística. Universidade Federal de Santa Catarina, Florianópolis, 2011.

PIRES, Adilson. Produção textual escrita em turma de correção de fluxo: um estudo sobre letramento e alfabetismo. Trabalho de conclusão de curso. Bacharelado em Letras - Português. Universidade Federal de Santa Catarina, 2013.

PONZIO, Augusto. Linguistica generale, scrittura letteraria e traduzione. Perugia: Guerra Edizione, 2007.

PONZIO, Augusto. Procurando uma palavra outra. São Carlos: Pedro e João Editores, 2010.

PONZIO, Augusto. A revolução bakhtiniana. São Paulo: Contexto, 2011. 
PONZIO, Augusto. Dialogando sobre diálogo na perspectiva bakhtiniana. São Carlos: Pedro e João Editores, 2012.

ROBERTSON, Roland. Globalization: social theory and global culture. London: SAGE, 1992.

STREET, Brian. Literacy in theory and practice. Cambridge: CUP, 1984.

STREET, Brian. Abordagens alternativas ao letramento e desenvolvimento. TELECONFERÊNCIA UNESCO BRASIL SOBRE 'LETRAMENTO E DIVERSIDADE', outubro de 2003.

VYGOTSKY, Lev Semenovich. The History of development of higher mental functions. RIEBER, Robert W. (Ed.). The collected works of L. S. Vygotsky. New York: Plenum Press, 1997. v. 4, p. 1-28. Original publicado em 1987.

VOLÓSHINOV, Valentín Nikoláievich. El marxismo y la filosofia del lenguaje. Buenos Aires: Ediciones Godot, 2009. Original publicado em 1929.

ZAVALA, Virginia. Quem está dizendo isso?: Letramento Acadêmico, identidade e poder na educação. In: VÓVIO, Cláudia; SITO, Luanda; DE GRANDE, Paula (Org.). Letramentos rupturas, deslocamentos e repercussões de pesquisas em linguística aplicada. Campinas, SP: Mercado de Letras, 2010. 


\section{Dossiê Práticas de letramento e identidades: estudos etnográficos}

